\title{
PREPARATION OF OAT SPELT XYLAN AND ITS APPLICATION AS ADDITIVE FOR ENHANCEMENT OF PAPER PROPERTIES
}

\author{
NGUYEN HOANG CHUNG and PHAN HUY HOANG \\ Hanoi University of Science and Technology, 1 Dai Co Viet Str., Hai Ba Trung, Hanoi, Vietnam \\ ×orresponding author: Phan Huy Hoang, hoang.phanhuy@hust.edu.vn
}

Received August 2, 2018

In this work, xylan extracted from oat spelt with a yield of approx. 17\% has been characterized for determining its properties. It was then applied as additive in paper-making by adding into elementary chlorine free bleached Kraft softwood pulp slurry. The study aims to investigate the influence of xylan on paper properties, based on its relative retention capacity on cellulose fibres during the paper-making process. Different xylan dosages were added right before sheet formation. The adsorbed amount of xylan and its relative retention capacity on the paper after the paper-making process have been quantified using mild acid hydrolysis and high-performance liquid chromatography. The adsorbed amount of xylan on paper increases with increasing xylan dosages, while the retention capacity reaches its highest value of $75 \%$, when $5 \%$ of xylan is added. Over this point, the retention is believed to be limited due to the saturation phenomenon, suggesting that higher amounts of xylan addition may not bring any further advantages to the mechanical properties of paper.

Keywords: acid hydrolysis, cellulose interaction, chemical modification, oat spelt xylan

\section{INTRODUCTION}

Xylan is the major component of hemicelluloses, one of the main substances of plant primary cell wall, besides cellulose, lignin and pectin. Xylan can be extracted from wood and non-wood materials, including annual plants, cereals, some algae or seaweeds. Non-wood materials, especially agricultural residues, are now drawing much attention since they are cheap and utilizing them can reduce the waste disposed into the environment. Moreover, these materials are recyclable, sustainable and reproducible. In this work, xylan isolated from oat spelt was used as a major material along bleached Kraft softwood pulp. Oat spelt, so-called oat husk or oat hulls, is a by-product of oat flake manufacturing. On the one hand, this cheap material can be collected in large quantities, since it constitutes up to $25 \%$ of the total grains, after the de-hulling stage in the production line. ${ }^{1}$ On the other hand, this is a potential source for xylan isolation due to its high content of hemicellulose (22-39\%) and relatively low amount of lignin (18-24\%). ${ }^{2}$

The diversity of xylan structure, in general, has been summarized and classified by Ebringeróva and co-workers. ${ }^{3,4}$ According to their work, xylan is generally composed of D- xylopyranosyl residues through $\beta-(1,3), \beta-(1,4)$ linkages or a combination of these two bonds. Moreover, xylan from different sources is also substituted with different side chains or functional groups, such as $\alpha$-D-glucuronic acid and/or its 4$O$-methyl derivative and/or arabinofuranosyl residues. Further studies on the structure, derivatization and application of oat spelt xylan (OSX), in particular, were conducted by Puls et $a l .{ }^{5}$ and Hettrich et al. ${ }^{6}$ Oat spelt xylan consists of arabinofuranosyl residues attached as branches to a xylopyranosyl polymeric backbone. The xylopyranosyl units are either mono-substituted at $\mathrm{O} 2$ or $\mathrm{O} 3$ positions or di-substituted at both $\mathrm{O} 2$ and $\mathrm{O} 3$ positions. Only $1.8-4.3 \%$ of $4-O$-methyl glucuronic acid is present in alkali extracted OSX. $^{7}$ Moreover, the ratio between xylose, arabinose, and 4-O-methyl glucuronic acid varies from plant to plant and from species to species; a ratio of 7.6:1:0.03 was specified for an OSX sample by Saake et ll $^{2}$

Xylan and its derivatives were proved to improve the mechanical properties of paper..$^{7-11}$ Schöberg and partners ${ }^{8}$ studied the role of xylan in the properties of paper made from bleached spruce Kraft pulp. They indicated that the 
bonding ability of the fibres was primarily influenced by the amount of xylan on the fibre surface. Moreover, the addition of xylan enhanced the strength properties of the fibre network. In another work, (glucurono) arabinoxylan from barley husk was shown to increase the tensile strength of Kraft pulp. ${ }^{10}$ Ramírez et $a l^{7}$ investigated the sorption of xylans from annual plants onto softwood Kraft pulp. According to their work, the addition of arabinoxylan from corncob and oat spelt led to an increase in the tensile and burst index, over the whole range of beating degrees of the pulp. Especially the addition of xylan before beating was believed to be more effective for the beating procedure, as well as for the strength properties of the paper. Cationic polysaccharides were seen to favor the fibre bonds through electrostatic interaction. ${ }^{12}$ In paper technology, cationic xylan derivatives have been used as a retention aid, ${ }^{13}$ or just normally as paper additives, which can improve the strength properties of paper. ${ }^{1,12,14,15}$

Although the role of xylan in improving paper strength has been demonstrated, it is necessary to understand the mechanism of its interaction with cellulose fibres during the paper-making process. A hypothesis of xylan interaction and retention on cellulose proposed by Linder et al. ${ }^{16}$ provided a clear point of view on this issue. In accordance with their hypothesis, when xylan is added into the pulp slurry, it goes through several stages, including attraction by cellulose surface, diffusion to and adsorption onto cellulose fibres. Regarding this topic, many studies on xylan adsorption and localization have been conducted. When modifying chemi-thermo-mechanical pulp with xylan, Henriksson and Gatenholm ${ }^{17}$ found that micro-sized structures of xylan particles were spread over the fibre surfaces as evidence for xylan-cellulose interaction. Moreover, the structure of xylan, especially the substitution, had a strong influence on its adsorption onto cellulosic surfaces, as specified by Kabel and Köhnke et $a l^{18,19}$ The distribution of adsorbed xylan on cellulose surface was recently studied by Miletzky et $a l .^{20}$ According to their work, precipitated xylan was heterogeneously and nonuniformly distributed on the tested cellulosic surfaces. They also suggested that the cellulose model films consisting of xylan could be observed via atomic force microscopy (AFM) measurement.

This work aims to prepare xylan from oat spelt and then investigate the influence of the as- obtained oat spelt xylan on paper mechanical properties, based on its remaining amount in paper, which has not been thoroughly studied so far. The relative retention capacity of xylan onto cellulose fibres was also evaluated. For this purpose, different amounts of oat spelt xylan were added into the pulp slurry during sheet formation in the paper-making process at a laboratory scale. The final papers, with different dosages of xylan added, were hydrolyzed with trifluoroacetic acid (TFA) under mild conditions. Three samples were prepared for the investigation: (1) handsheets without added xylan, (2) handsheets with different amounts of added xylan, and (3) xylan itself. The sugar contents, including xylose, arabinose, mannose and galactose, were analyzed by high performance liquid chromatography (HPLC). The amount of xylan, which was retained on cellulose fibres after the addition, was calculated based on the difference between the sugar content and total sugar of these three mentioned samples, especially xylose.

\section{EXPERIMENTAL}

\section{Materials}

Elementary chlorine-free (ECF) bleached Kraft softwood pulp, purchased from Zellstoff Stendal $\mathrm{GmbH}$, was used for the paper-making process. The pulp was received in the form of pulp sheets with dry content of about $95 \%$.

Oat spelt was purchased from Peter Kölln KGaA Elmshorn Company.

\section{Preparation of pulp slurry}

Before use, the pulp sheet was torn into small pieces and soaked in tap water. This step might take up to 24 hours in order to allow the fibres to completely swell. Tap water was used to bring the experiment close to industrial conditions, where no distilled water is used while producing paper. Wet pulp was then mixed well at a high speed for 5 minutes, before transferring it to a milling machine. An appropriate milling time was set to obtain pulp with a refining degree of $18{ }^{\circ} \mathrm{SR}$ (according to an internal manual instruction issued by the Institute of Plant and Wood Chemistry, TU Dresden). After that, the milled pulp was dewatered by centrifugation, which resulted in a $30.8 \%$ dry content pulp. The procedure was performed by Mr. Paul-Gerhard Weber (Institute of Wood and Paper Technology, TU Dresden, Germany) and Dr. Christian Bäurich (Institute of Plant and Wood Chemistry, TU Dresden, Germany). The pulp was then disintegrated for 2 minutes in a disintegrator to obtain a homogeneous pulp suspension. The pulp slurry (3 $\mathrm{g} / \mathrm{L}$ consistency) was prepared in a $10-\mathrm{L}$ tank by filling with water. 


\section{Xylan isolation from oat spelt}

Oat spelt xylan was prepared according to the wellknown procedure specified by Puls et al. ${ }^{5}$ The extraction was carried out in a 5-L ploughshare mixer designed by Loedige Company. The oat spelt (373 g) was dispersed in $2.5 \mathrm{~L}$ of sodium hydroxide solution $(\mathrm{NaOH}, 5 \%$, w/w). The dispersion was then heated during moderate mixing at $90{ }^{\circ} \mathrm{C}$ for 90 minutes. Xylan was precipitated from the extract by adding 5.4 $\mathrm{L}$ of a methanol-water mixture $(60 \%, \mathrm{v} / \mathrm{v})$ and separated by centrifugation. Subsequently, the precipitate was treated with $9.97 \mathrm{~g}$ of hydrogen peroxide solution $\left(\mathrm{H}_{2} \mathrm{O}_{2}, 35 \%\right.$, v/v) together with 2.32 $\mathrm{g}$ of $\mathrm{NaOH}$ at $90{ }^{\circ} \mathrm{C}$ for 2 hours in $1.2 \mathrm{~L}$ of the methanol-water mixture. The mixture was then again cooled down to room temperature and centrifuged. The product was isolated and washed three times with $2 \mathrm{~L}$ of the methanol-water mixture and twice with $2 \mathrm{~L}$ of pure methanol. Approx. $65 \mathrm{~g}$ of the product was obtained after vacuum drying at $40{ }^{\circ} \mathrm{C}$.

Before use, the xylan was dispersed into water with magnetic stirring to form a homogeneous suspension. Heating at around $50{ }^{\circ} \mathrm{C}$ might be needed to shorten the dissolving time. It is noted here that hydrogen peroxide in alkaline medium is known as a bleaching agent in paper technology, as it removes partly or completely lignin. However, the use of hydrogen peroxide in combination with sodium hydroxide, as used in this extraction process, can dissolve and hydrolyze hemicelluloses, causing a reduction in the molecular weight of the product. $^{21-23}$

\section{Handsheet making and testing}

Handsheets were produced with a lab-scale papermaking machine Rapid-Köthen Automatik. The process was carried out following standard ISO 5269$2 .^{24}$ Each sheet was made with a specific amount of the prepared pulp suspension in order to obtain final paper sheets with a basis weight of $80 \mathrm{~g} / \mathrm{m}^{2}$. Two groups of samples were produced in this experiment: (1) paper sheets with OSX added as mentioned above, and (2) paper sheets without xylan addition. For the former, the OSX suspension at different dosages was added into the pulp right before the sheet formation stage of the paper-making procedure. The xylan dosages of 1 , 2,5 and $10 \%$ were percentages by mass based on the dry weight of the pulp (i.e. if each sheet weighs about $2.4 \mathrm{~g}$, papers with $1,2,5$ and $10 \%$ of xylan added will theoretically contain $0.024 \mathrm{~g}, 0.048 \mathrm{~g}, 0.120 \mathrm{~g}$ and $0.240 \mathrm{~g}$ of xylan, respectively). The maximum dose of $10 \%$ was chosen based on the fact that xylan isolation and its application as a paper additive are still very pricey at this moment. In addition, to the best of the authors' knowledge, $10 \%$ is the highest dosage of xylan used as a paper additive in many other studies, for instance, $3 \%$ by Kataja-aho et al., ${ }^{25} 9 \%$ by Schwikal et al., ${ }^{12} 10 \%$ by Han et al., ${ }^{26}$ and $6 \%$ by Deutschle et al. ${ }^{15}$ Moreover, the low solubility of the alkaline extracted OSX in water, especially at high concentrations, also influences significantly its adsorption onto the cellulose fibres. ${ }^{18}$ In all the cases, 5 replicates resulting in 5 sheets were produced.

The finished paper sheets were kept in a climatecontrolled room $\left(23{ }^{\circ} \mathrm{C}\right.$, humidity $\left.50 \%\right)$ according to ISO $187^{27}$ before mass, thickness, tensile strength, and tearing resistance were determined following ISO 536:2002, ISO 534:2011, ISO 1924-2:2008, and ISO 1974:2012 standards, respectively. ${ }^{28-31}$ Tensile and tear indices are the most significant parameters for paper mechanical properties, besides burst strength. However, tensile and burst index often share the same trend (i.e. they both increase with increasing xylan addition, ${ }^{21-23}$ therefore only the first two mentioned parameters were investigated in this work.

All the sheets were produced and tested at the Institute of Wood and Paper Technology, TU Dresden, Germany.

\section{Mild hydrolysis with trifluoroacetic acid (TFA) for sugar analysis by HPLC}

This experiment aimed to produce monosaccharides from polysaccharide samples for further sugar analysis by HPLC. The hydrolysis can be carried out by using acids or enzymes. For economic reasons, acids are more common, especially sulfuric acid. However, sulfuric acid has many drawbacks. ${ }^{32}$ First of all, the use of sulfuric acid might destroy the sugars and the reaction between monosaccharides and sulfuric acid reduces the yield of the hydrolysis. Second, the process using sulfuric acid requires a timeconsuming procedure to remove the acid after hydrolysis. In comparison with sulfuric acid, trifluoroacetic acid (TFA) has several advantages. The reaction with TFA requires a shorter time. On the other hand, TFA is volatile and therefore can be easily removed by evaporation without any traditional neutralization. ${ }^{33,34}$

The hydrolysis was performed according to the procedure described by Fengel et al. ${ }^{35}$ A dried paper sample $(20 \mathrm{mg})$ was placed into a $50-\mathrm{mL}$ round bottom flask, where $3 \mathrm{~mL}$ of concentrated TFA solution (99\%, p.a.) was added subsequently. The mixture was allowed to stand overnight at room temperature. After that, the TFA solution was diluted to $80 \%$ concentration by adding $1.108 \mathrm{~mL}$ of distilled water. The reaction was conducted at $105{ }^{\circ} \mathrm{C}$ for 35 minutes. Subsequently, the solution was diluted the second time to a concentration of $30 \%$ by adding $9.233 \mathrm{~mL}$ of distilled water. The reaction was maintained at $105{ }^{\circ} \mathrm{C}$ for two more hours.

After the required time, the flask was cooled down to room temperature before the sample was washed. The washing process was conducted in a rotary evaporator at $40{ }^{\circ} \mathrm{C}$. At first TFA was removed and then distilled water was added to wash the product until it was free of acid. The clean samples were kept in a refrigerator until later analysis by HPLC. 
Sugar analysis and determination of relative retention capacity of xylan on paper

The sugar composition of the hydrolyzed samples, including xylose, arabinose, mannose and galactose, was analyzed using an Agilent 1200 HPLC series system, equipped with an LC-MS detector and a ReproGel $\mathrm{Pb}$ column. The hydrolyzed sample was filtered through a $0.45 \mu \mathrm{m}$ polytetrafluoroethylene (PTFE) syringe filter and eluted with distilled water. The glucose content is not mentioned here, since it cannot be determined precisely with this method. On the one hand, this sugar cannot be depolymerized completely into monomers using mild hydrolysis. On the other hand, the origin of glucose, which can be from starch, hemicellulose or cellulose, cannot be specified.

The amount of xylan on adsorbed cellulose was calculated based on the difference between the xylose content of the paper with added xylan and the pure paper. The relative retention capacity of the xylan on paper is the relation between the adsorbed amount of xylan and the actual amount of xylose present in the amount of xylan added into paper. This calculation was also applied for arabinose.

\section{Fourier transform (FT) Raman spectroscopy}

The spectra of the OSX were recorded using a Bruker MultiRAM III NIR FT-Raman spectrometer. The power of the laser source was $150 \mathrm{~mW}$. For each measurement, 200 scans were performed at a resolution of $4 \mathrm{~cm}^{-1}$. The resulting spectra were normalized and performed with OriginPro software, version 8.6.0.

\section{Size exclusion chromatography (SEC)}

Molecular mass data of the xylan were obtained by SEC analysis using DMSO-water (90\%, v/v) and 0.05 $\mathrm{M} \mathrm{LiBr}$ additive, as published previously by Saake $e t$ $a l .{ }^{36}$ Pullulan standards and glucose were used for calibration. A polymer standard service (PSS) set column was used with the following parameters: GRAM 100, $3000\left(8 \times 300 \mathrm{~mm}^{2}\right)$ and guard column $(8$ $\times 50 \mathrm{~mm}^{2}$ ). The flow rate was $0.4 \mathrm{~mL} / \mathrm{min}$ at $60{ }^{\circ} \mathrm{C}$. Xylan was dissolved in the eluent in a temperaturecontrolled shaker for 1 hour at $95{ }^{\circ} \mathrm{C}$, followed by 23 hours at $40{ }^{\circ} \mathrm{C}$. The sample was filtered using a regenerated cellulose membrane. The measurement was conducted by the group of Prof. Saake (Unversity of Hamburg, Germany).

\section{Xylan bleaching}

This step was performed only to confirm the structure of the oat spelt xylan. The bleaching process was conducted using chlorine dioxide. Approx. $1 \mathrm{~g}$ of xylan was placed in a cylinder flask. Subsequently, 60 $\mathrm{mL}$ of active chlorine dioxide solution $(10 \mathrm{~g} / \mathrm{L}, \mathrm{pH} \sim$ 2.4) was added. The reaction was performed at $70{ }^{\circ} \mathrm{C}$ in a water bath for 2 hours under stirring. After the reaction time, the xylan was separated from the liquid part by using a $0.45 \mu \mathrm{m}$ cellulose acetate membrane filter, $\phi 47 \mathrm{~mm}$ (Carl Roth $\mathrm{GmbH}$ Co. KG). The product was then washed several times with distilled water before recording its spectra by FT-Raman spectroscopy.

\section{RESULTS AND DISCUSSION Characterization of raw materials Monosaccharide composition}

The oat spelt xylan was hydrolyzed with TFA for sugars analysis by HPLC. The relative composition of sugars, including xylose, arabinose, mannose and galactose, of the sample is presented in Table 1 .

A small amount of arabinose (6.6\%) indicates the presence of arabinose side chains attached on the backbone of the xylan. The xylose-toarabinose ratio implies that one arabinose side chain substitutes every eleventh xylose unit of the xylan backbone. This ratio of 10 was detected by Deutschle et al. ${ }^{15}$ when they characterized an OSX sample. Galactose contributes with an only insignificant amount, while mannose is not detected. Low content of galactose is assumed from arabinogalactan, which could be covalently linked to the protein present in the xylan. ${ }^{15,37}$

The rest of the sugar composition could be glucose, which cannot be detected correctly with the used method and other sugars.

Table 1

Neutral sugar composition of oat spelt xylan

\begin{tabular}{lcccc}
\hline Single sugars $(\%)$ & Xylose & Arabinose & Galactose & Mannose \\
\hline Oat spelt xylan & $73.4 \pm 3.5$ & $6.6 \pm 0.7$ & $0.4 \pm 0.0$ & - \\
\hline
\end{tabular}




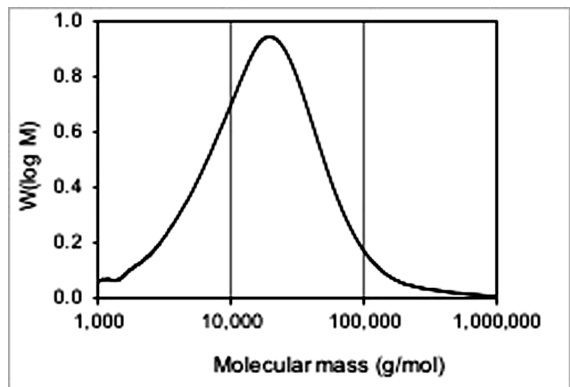

Figure 1: Molecular mass distribution of oat spelt xylan (signal obtained by SEC with an RI detector, using pullulan standards and glucose for calibration, and a xylan concentration of $5.62 \mathrm{~g} / \mathrm{L}$ )

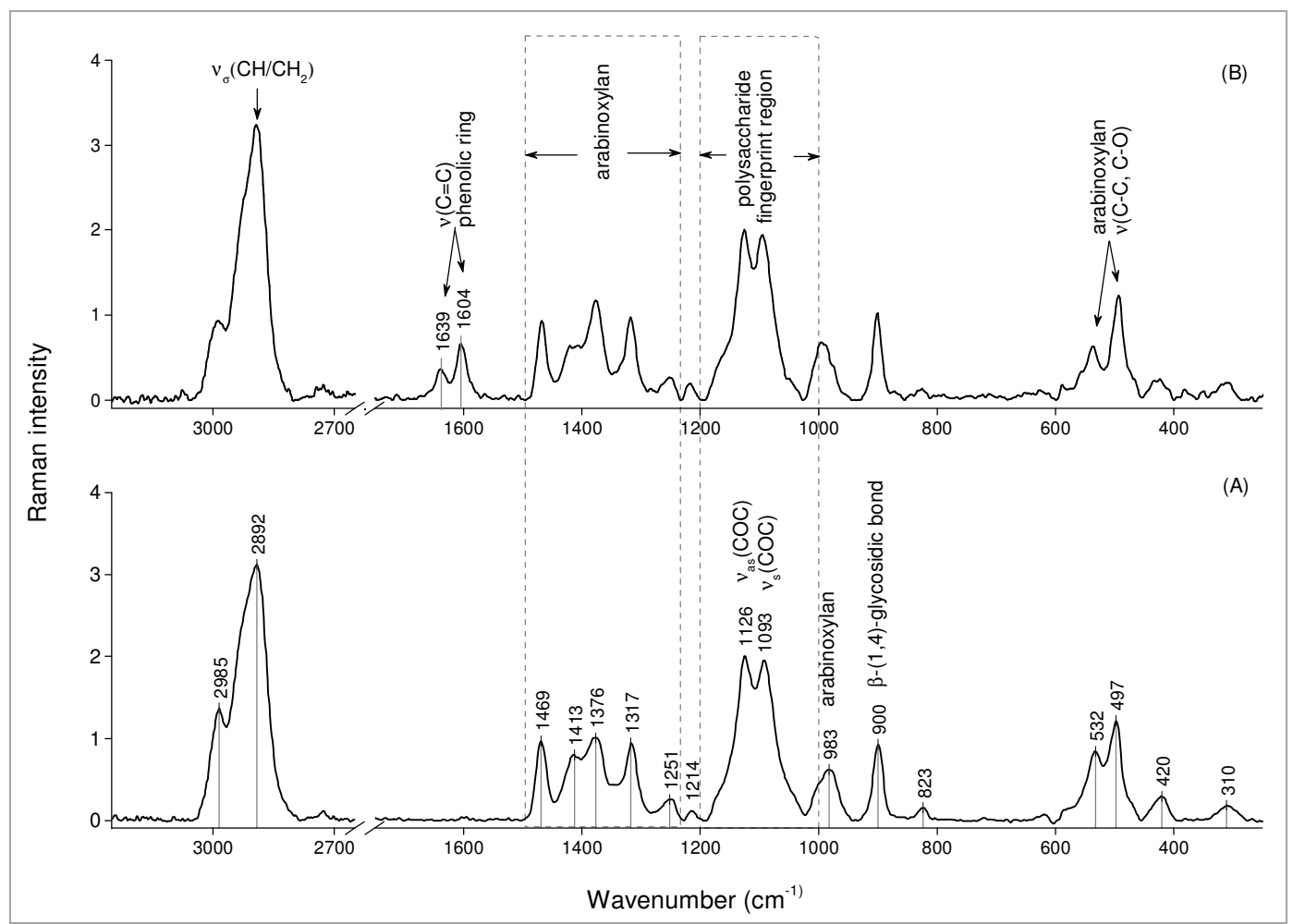

Figure 2: FT-Raman spectra of oat spelt xylan after (A) extra-bleaching and before it (B)

Molecular weight and molecular weight distribution

The molecular mass distribution of the OSX obtained by SEC is illustrated in Figure 1. The data reveal an average molecular mass of 22000 $\mathrm{g} / \mathrm{mol}$ for the OSX. This molecular mass is in the range of those typical for xylans from annual plants, e.g. $28000-29000 \mathrm{~g} / \mathrm{mol}$ for barley hemicellulose $^{5}$ and $25400 \mathrm{~g} / \mathrm{mol}$ for DMSO extracted oat spelt xylan. ${ }^{36}$

However, the molecular weight of oat spelt xylan, in general, can be different depending on the raw materials, as well as the extraction method and conditions. For instance, an OSX sample with molecular weight of $79200 \mathrm{~g} / \mathrm{mol}$ was isolated by Hettrich et al. ${ }^{6}$ Xylans from hardwoods normally have higher molecular weight, of around $30000-36000 \mathrm{~g} / \mathrm{mol}^{38-40}$

\section{Molecular structure}

The molecular structure of the OSX was confirmed by FT-Raman spectroscopy. Figure 2 depicts the FT-Raman spectra of the OSX before and after the extra-bleaching procedure.

Major peaks at 497, 532, 900, 983, 1093-1126, and 1251-1469 $\mathrm{cm}^{-1}$ are observed. These are typical bands found very often in arabinoxylan. ${ }^{41,42}$ The bands at 497 and $532 \mathrm{~cm}^{-1}$ are assigned to $\mathrm{C}-\mathrm{C}$ and $\mathrm{C}-\mathrm{O}$ stretching vibrations. The presence of the $\beta$ - $(1,4)$-glycosidic bond of the xylan backbone is identified by the peak at around $900 \mathrm{~cm}^{-1}$. A pair of bands observed 
at $1093 / 1126 \mathrm{~cm}^{-1}$ is also assigned to glycosidic linkages, involving the $\mathrm{C}-\mathrm{O}$ stretching vibration. These are typical peaks assigned to the asymmetric and symmetric stretching vibration of $\mathrm{COC}$ and belong to the polysaccharide fingerprint region, which is usually seen in the range of $1000-1200 \mathrm{~cm}^{-1} .42-44$ These peaks usually appear in xylan samples, including wheat arabinoxylan, as well as some hardwood xylans. ${ }^{42,44,45}$

When using hulls from annual plants as starting materials for xylan isolation, the products may contain proteins, phenolics and other soluble polysaccharides. ${ }^{3,45}$ As an illustration, a double peak observed at $1604 / 1639 \mathrm{~cm}^{-1}$ is characterized as a phenolic ring. According to Kačuráková et al. ${ }^{45}$ ferulic acid has characteristic adsorption bands at 1517, 1600, 1620 and $1690 \mathrm{~cm}^{-1}$. Further, Himmelsbach and Atkin ${ }^{46}$ found that one of the typical peaks of ferulic acid appears at 1602 $\mathrm{cm}^{-1}$, which is almost the same position as the lignin band at $1601 \mathrm{~cm}^{-1}$. As mentioned before, hemicelluloses from annual plants and cereals may contain ferulic acid groups, which are covalently linked to arabinose residues via the ester linkage. ${ }^{47,48}$ However, these ester bonds are easily broken during the xylan isolation due to the presence of alkaline and peroxide, especially when using oat spelt as raw material. ${ }^{47,49-51}$ Therefore, the doublet at $1604 / 1639 \mathrm{~cm}^{-1}$ could be identified for lignin residue. To confirm this hypothesis, an extra-bleaching process using chlorine dioxide was carried out for the xylan, as described in the experimental section. As expected, these peaks are absent from the spectrum of bleached xylan, as seen from Figure $2 \mathrm{~A}$. It should be noted that hydrogen peroxide, in combination with sodium hydroxide, does not only remove lignin, but can also dissolve and hydrolyze hemicelluloses, resulting in lower molecular weight of the isolated product. ${ }^{3}$ As a result, the bleaching process should only reach a level where the yield is high, and the product has an acceptable brightness.

In addition, a very strong, intense band observed at $2892 \mathrm{~cm}^{-1}$ is assigned to $\mathrm{CH} / \mathrm{CH}_{2}$ asymmetric stretching vibration, which is also typical of carbohydrates.

\section{Relative retention capacity of oat spelt xylan on cellulose}

In order to study the retention of the oat spelt xylan on cellulose, paper sheets with and without xylan addition were prepared according to the described method. In this process, only a part of the xylan was adsorbed on the cellulose surface by creating bonds with the fibres. This experiment aimed to evaluate how much xylan was preserved on the cellulose fibres, expressed as relative retention capacity.

Figure 3 illustrates the sugar content present in the paper samples with the addition of different xylan dosages. As follows from Figure 3, xylose and mannose are two major sugars present in the paper samples, which can be detected with this method. The xylose content increases significantly with increasing xylan doses. On the one hand, this trend of xylose is more obvious than the other sugars because xylose constitutes the major part of the xylan with $73 \%$, as presented in Table 1. On the other hand, the presence of xylan is believed to create more hydrogen bonds with cellulose fibres resulting in the increased amount of xylose when increasing xylan dosage. There is almost no change in mannose, since this sugar is not present in the xylan used on its own (data shown in Table 1). This is just the preexisting mannose present in the paper itself. Galactose does not seem to be affected by the content of xylan, since this sugar constitutes only a small part of the xylan, as well as of the paper sheets.

\section{Relative retention capacity}

As mentioned earlier, the relative retention capacity of the OSX on paper is defined as the relation between the adsorbed amount of xylose and the actual amount of xylose present in the xylan added into paper. The determination is based on xylose as this sugar makes up the major composition of xylan. The correlation between the amount of xylan retained on the paper and the xylan dosages is illustrated in Figure 4. It can be seen obviously from Figure 4 that the adsorbed amount of xylan increases with increasing xylan addition. It reaches the highest value of $2.8 \%$ when $10 \%$ of xylan was added. This is in agreement with the xylose content of the papers with different amounts of added xylan, as shown in Figure 3.

This is comparable with the work of Han et $a l .,{ }^{26}$ who studied the adsorption of birch xylan onto hardwood pulp. According to their findings, the amount of adsorbed xylan started to decrease when adding more than $8 \%$ of xylan. The pulp properties (hardwood pulp vs. softwood pulp) and the xylan type (wood and non-wood xylan) are believed to considerably affect the adsorption ability of xylan. In addition, this procedure also 
depends on the molecular weight, degree of substitution, and substitution patterns of the added xylan. ${ }^{16,18,19,52}$ Further investigation on this issue is of interest, but beyond the scope of this study.

The relative retention capacity of xylan as a function of the xylan dosage is depicted in Figure 5. Surprisingly, the highest amount of xylan retained on paper does not result in the highest relative retention capacity of the xylan. Nearly $48 \%$ of xylose remained on paper when $5 \%$ of xylan was added, which corresponds to $1.7 \%$ of the adsorbed amount of xylan. This is also the highest value among the used dosages of xylan in this work. Above this point (i.e. 10\% of xylan dosage), the retention capacity starts to decrease. Arabinose, the sugar that appears once at every eleventh xylose unit of the xylan backbone, also shares the same trend with the highest retention capacity of approx. $18 \%$ when $5 \%$ of xylan was added. This phenomenon can be explained by a hypothesis of xylan adsorption limitation on cellulose fibres. It is well known that paper is formed by a fibre network among celluloses or holocelluloses through hydrogen bonds, which can be increased by the addition of xylan. This process, however, can have a saturation state. When this limitation is reached, xylan can no longer create linkages with the fibres. These

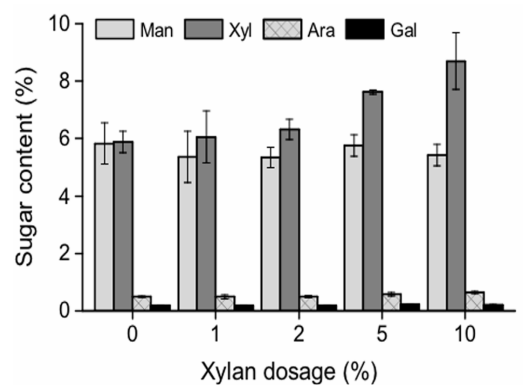

Figure 3: Sugar content of paper sheets (pulp refining degree of $18{ }^{\circ} \mathrm{SR}$ ) with different xylan dosages

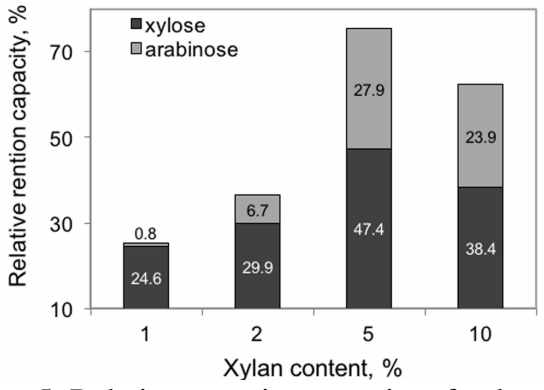

Figure 5: Relative retention capacity of xylan based on xylose and arabinose in correlation with adsorbed amount of xylan on paper results indicate that higher amounts of xylan addition (i.e. from $10 \%$ onwards) result in lower retention capacity of xylan in paper. This has a special meaning in paper industry since the cost of xylan isolation and its application as a paper additive is still rather high. Further experiments on papers with higher dosages of xylan addition, e.g. $12-15 \%$, will be conducted in our future work to prove this hypothesis.

\section{Influence of xylan addition on paper strength properties}

Hemicellulose is well known as a paper strength enhancer, especially for tensile strength by acting as a glue between cellulose fibres. ${ }^{43}$ As a paper additive, xylan has shown its ability to improve the mechanical properties of paper.

In accordance with the data shown in Figure 6, the tensile index of paper is slightly increased with increasing xylan content, while tear resistance is not significantly influenced. This is obvious because tensile strength is primarily dependent on the degree of fibre bonding, which is mostly based on hydrogen linkages. The addition of xylan to paper is believed to strengthen the fibre network by increasing the number of hydrogen bonds between the polysaccharides. ${ }^{26}$

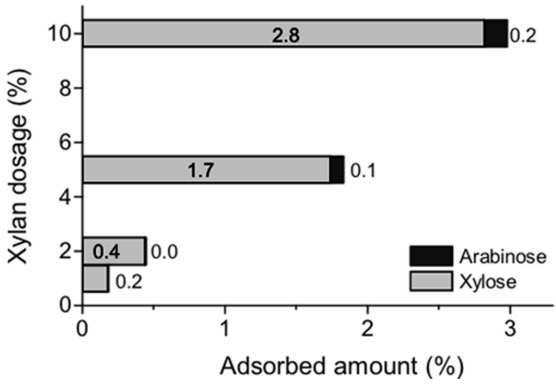

Figure 4: Adsorbed amount of xylan based on xylose and arabinose, in correlation with xylan dosages

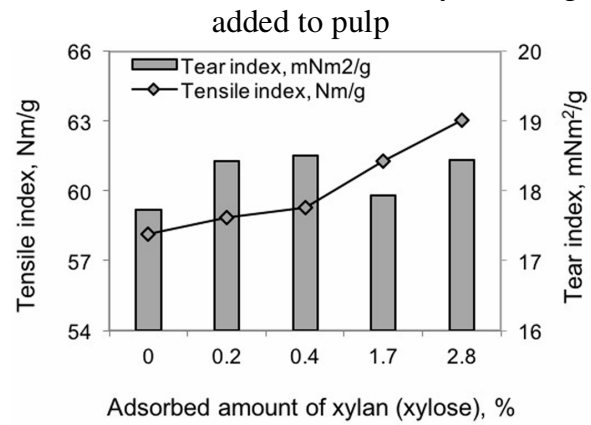

Figure 6: Influence of oat spelt xylan dosage on tensile and tear index 
Unlike tensile strength, tear resistance strongly depends on the strength of individual fibres. The addition of xylan, in this case, might not bring any improvement in tear index, since xylan is a lower molecular weight polysaccharide, compared to cellulose. This is also in agreement with the adsorbed amount of the xylan on cellulose, as presented earlier.

These results suggest that a higher amount of xylan adsorbed on paper might lead to a higher tensile strength of the paper. Similar trends have been published previously by Ramírez et al., ${ }^{7}$ who investigated the sorption of corncob and oat spelt arabinoxylan onto softwood Kraft pulp, and later by Han et al., ${ }^{26}$ who used birch xylan to modify eucalyptus pulp.

\section{CONCLUSION}

From the research that has been performed, the role of xylan in improving paper properties in correlation with the remaining percentage of xylan on cellulose has been proved, especially for the tensile strength. It is possible to conclude that the relative retention capacity of oat spelt xylan on paper depends on xylan dosages under the particular conditions used. The amount of xylan adsorbed on paper increases with increasing xylan dosages. This is also reflected in the improvement of the tensile index of the papers. However, the retention capacity of oat spelt xylan does not follow the same trend as the adsorbed amount, since it reached the highest value when only 5\% of xylan was added. This finding suggests that very high amounts of xylan addition may not yield any further advantages to the adsorption, which is perhaps explained by the fact that the saturation level has been reached. In addition, the proposed method for determination of xylan adsorption on paper can be readily used with xylans from annual plants, such as oat spelt and wheat straw. These findings may provide a practical approach to using oat spelt xylan as an alternative additive in paper technology, considering economic aspects.

In our future research, we intend to conduct further investigations to prove the adsorption saturation hypothesis, which has been raised in this work. The quantitative method to determine the retention capacity of pure xylan on paper will be developed to apply to other derivatives of xylan, including ionic and acidic xylans.
ACKNOWLEDGEMENTS: The authors would like to thank Dr. Christian Bäurich (Institute of Plant and Wood Chemistry, Dresden University of Technology, Germany) and Mr. Paul-Gerhard Weber (Institute of Wood and Paper Technology, Dresden University of Technology, Germany) for preparing the milled pulp. We would also like to thank Prof. Bodo Saake (University of Hamburg, Germany) for his help with SEC analysis. Financial support from the Ministry of Education and Training (Vietnam) and the Graduate Academy (Dresden University of Technology, Germany) is gratefully acknowledged. Last but not least, we would like to thank Prof. Steffen Fischer, Dr. Maren Freese (TU Dresden), and Dr. Kay Hettrich (Fraunhofer Institute for Applied Polymer Research) for their invaluable support for the work.

\section{REFERENCES}

1 R. K. Thompson, A. F. Mustafa, J. J. McKinnon, D. Maenz and B. Rossnagel, Can. J. Anim. Sci., 80, 377 (2000), https://doi.org/10.4141/A99-132

2 B. Saake, N. Erasmy, E. Schmekal and J. Puls, in "Hemicelluloses Science and Technology", edited by P. Gatenholm and M. Tenkanen, Vol. 80, pp. 52-65, American Chemical Society, Washington DC, 2003, https://doi.org/10.1021/bk-2004-0864.fw001

3 A. Ebringerová and T. Heinze, Macromol. Rapid Commun., 21, 542 https://doi.org/10.1002/15213927(20000601)21:9\%3C542::AIDMARC542\%3E3.0.CO;2-7

4 A. Ebringerová, Macromol. Symp., 232, 1 (2005), https://doi.org/10.1002/masy.200551401

5 J. Puls, N. Schröder, A. Stein, R. Janzon and B. Saake, Macromol. Symp., 232, 85 (2005), https://doi.org/10.1002/masy.200551410.

6 K. Hettrich, S. Fischer, N. Schröder, J. Engelhardt, U. Drechsler et al., Macromol. Symp., 232, 37 (2006), https://doi.org/10.1002/masy.200551405

7 F. Ramírez, J. Puls, V. Zúñiga and B. Saake, Holzforschung, $\quad$ 62, $329 \quad$ (2008), https://doi.org/10.1515/HF.2008.059

8 C. Schönberg, T. Oksanen, A. Suurnäkki, H. Kettunen and J. Buchert, Holzforschung, 55, 639 (2001), https://doi.org/10.1515/HF.2001.104

S. Danielsson, Thesis, KTH School of Chemical Science and Engineering, Stockholm, Sweden (2006), http://kth.diva-

portal.org/smash/record.jsf?pid=diva2:9706

10 T. Köhnke, C. Pujolras, J. P. Roubroeks and P. Gatenholm, Cellulose, 15, $537 \quad$ (2008), https://doi.org/10.1007/s10570-008-9209-5

11 J.-L. Ren, F. Peng, R.-C. Sun and J. F. Kennedy, Carbohyd. Polym., 75, $338 \quad$ (2009), 
https://doi.org/10.1016/j.carbpol.2008.08.011

12 K. Schwikal, T. Heinze, B. Saake, J. Puls, A. Kaya et al., Cellulose, 18, $727 \quad$ (2011), https://doi.org/10.1007/s10570-011-9526-y

13 A. Ebringerová, Z. Hromádková, M. Kačuráková and M. Antal, Carbohyd. Polym., 24, 301 (1994), https://doi.org/10.1016/0144-8617(94)90075-2

14 T. Köhnke, Thesis, Chalmers Univesrity of Technology, Gothenburg, Sweden (2010), https://research.chalmers.se/en/publication/109278

15 A. L. Deutschle, K. Römhild, F. Meister, R. Janzon, C. Riegert et al., Carbohyd. Polym., 102, 627 (2014), https://doi.org/10.1016/j.carbpol.2013.12.016 16 A. Linder, R. Bergman, A. Bodin and P. Gatenholm, Langmuir, 19, $5072 \quad$ (2003), https://doi.org/10.1021/la0341355

$17 \AA$ A. Henriksson and P. Gatenholm, Cellulose, 9, 55 (2002), https://doi.org/10.1023/A:1015826713109

18 M. A. Kabel, H. van den Borne, J.-P. Vincken, A. G. J. J. Voragen and H. A. Schols, Carbohyd. Polym., 69, 94

(2007),

https://doi.org/10.1016/j.carbpol.2006.09.006

19 T. Köhnke, А. Östlund and H. Brelid, Biomacromolecules, 12, $2633 \quad$ (2011), https://doi.org/10.1021/bm200437m

20 A. Miletzky, M. Punz, A. Zankel, S. Schlader, C. Czibula et al., Cellulose, 22, 189 (2014), https://doi.org/10.1007/s10570-014-0472-3

${ }^{21}$ A. Ebringerová and Z. Hromádková, Holz als Rohund Werkst., 47, 355 (1989), https://doi.org/10.1007/BF02606031

22 A. Ebringerová and Z. Hromádková, Biotechnol. Genet. Eng. Rev., 16, $325 \quad$ (1999), https://doi.org/10.1080/02648725.1999.10647982

23 R. C. Sun, J. Tomkinson, P. L. Ma and S. F. Liang, Carbohyd. Polym., 42, $111 \quad$ (2000), https://doi.org/10.1016/S0144-8617(99)00136-8 24 ISO5269-2:2004

25 J. Kataja-aho, S. Haavisto, J. Asikainen, S. Hyvärinen and S. Vuoti, Bioresources, 7, 1713 (2011), https://doi.org/10.15376/biores.7.2.1713-1728

26 W. Han, C. Zhao, T. Elder, K. Chen, R. Yang et al., $\begin{array}{lllll}\text { Carbohyd. } & \text { Polym., } & \mathbf{8 8}, & 719 & \text { (2012), }\end{array}$ https://doi.org/10.1016/j.carbpol.2012.01.025

27 ISO187:1990

28 ISO536:2012

29 ISO534:2011

30 ISO1924-2:2008

31 ISO1974:2012

32 I. M. Morrison, Phytochemistry, 27, 1097 (1988), https://doi.org/10.1016/0031-9422(88)80281-4

33 P. Albersheim, D. J. Nevins, P. D. English and A. Karr, Carbohyd. Res., 5, $340 \quad$ (1967), https://doi.org/10.1016/S0008-6215(00)80510-8

34 D. Fengel and G. Wegener, Hydrolys. Cellul. Mech. Enzym. Acid Catal., 181, 145 (1979), https://doi.org/10.1021/ba-1979-0181.ch007

35 D. Fengel, G. Wegener, A. Heizmann and M. Przyklenk, Holzforschung, 31, 65 (1977), https://doi.org/10.1515/hfsg.1977.31.3.65

36 B. Saake, T. Kruse and J. Puls, Bioresour. Technol., $\quad 80, \quad 195 \quad$ (2001), https://doi.org/10.1016/S0960-8524(01)00089-X

37 B. Fincher and B. A. Stone, Aust. J. Biol. Sci., 27, 117 (1974), https://doi.org/10.1071/BI9740117

38 T. Koshijima, T. E. Timell and M. Zinbo, J. Polym. Sci. Part C Polym. Symp., 11, 265 (1965), https://doi.org/10.1002/polc.5070110119

39 D. V. Evtuguin, J. L. Tomás, A. M. S. Silva and C. P. Neto, Carbohyd. Res., 338, 597 (2003), https://doi.org/10.1016/S0008-6215(02)00529-3

${ }^{40}$ P. C. C. Pinto, D. V. V. Evtuguin and C. P. Neto, Carbohyd. Polym., 60, $489 \quad$ (2005), https://doi.org/10.1016/j.carbpol.2005.03.001

41 O. Piot, J.-C. Autran and M. Manfait, J. Cereal Sci., 32, 57 (2000), https://doi.org/10.1006/jcrs.2000.0314

42 C. Barron, P. Robert, F. Guillon, L. Saulnier and X. Rouau, Carbohyd. Res., 341, 1186 (2006), https://doi.org/10.1016/j.carres.2006.03.025

43 S. A. Rydholm, "Pulping Processes", Interscience Publishers, New York, 1965, pp. 1143-1144, https://www.cabdirect.org/cabdirect/abstract/19650607 049

${ }^{44}$ Q. Shen, L. Zhong and J.-F. Hu, Colloid. Surface. B, 39, $195 \quad$ (2004), https://doi.org/10.1016/j.colsurfb.2004.10.003

45 M. Kačuráková, N. Wellner, A. Ebringerová, Z. Hromádková, R. H. Wilson et al., Food Hydrocoll., 13, 35 (1999), https://doi.org/10.1016/S0268005X(98)00067-8

46 D. S. Himmelsbach and D. E. Akin, J. Agric. Food Chem., 46, 991 (1998), https://doi.org/10.1021/jf970656k

47 M. M. Smith and R. D. Hartley, Carbohyd. Res., 118, 65 (1983), https://doi.org/10.1016/00086215(83)88036-7

48 M. S. Izydorczyk and C. G. Biliaderis, Carbohyd. Polym., 28, 33 (1995), https://doi.org/10.1016/01448617(95)00077-1

49 A. C. Salomonsson, O. Theander and P. Aman, $J$. Agric. Food Chem., 26, $830 \quad$ (1978), https://doi.org/10.1021/jf60218a010

50 R. C. Sun, X. F. Sun and S. H. Zhang, J. Agric. Food Chem., 49, $5122 \quad$ (2001), https://doi.org/10.1021/jf010500r

51 F. Xu, R.-C. Sun, J.-X. Sun, C.-F. Liu, B.-H. He et al., Anal. Chim. Acta, 552, 207 (2005), https://doi.org/10.1016/j.aca.2005.07.037

52 A. Paananen, M. Ôsterberg, M. Rutland and T. Tammelin, in "Hemicelluloses Science and Technology", edited by P. Gatenholm and M. Tenkanen, ACS Symposium Series, American Chemical Society, Washington DC, 2004, pp. 269-290, https://doi.org/10.1021/bk-2004-0864.ch018 